\title{
Bacterial Outer Membrane Vesicles Induce Plant Immune Responses
}

\author{
Ofir Bahar, ${ }^{1}$ Gideon Mordukhovich, ${ }^{1,2}$ Dee Dee Luu, ${ }^{3}$ Benjamin Schwessinger,,${ }^{3,4}$ Arsalan Daudi, ${ }^{3}$ \\ Anna Kristina Jehle, ${ }^{5}$ Georg Felix, ${ }^{5}$ and Pamela C. Ronald ${ }^{3,4}$ \\ ${ }^{1}$ Department of Plant Pathology and Weed Science, Agricultural Research Organization, Volcani Center, POB 6, Bet-Dagan, \\ 502500, Israel; ${ }^{2}$ The Robert H. Smith Faculty of Agriculture, Food and Environment, The Hebrew University of Jerusalem, \\ Rehovot, Israel; ${ }^{3}$ Department of Plant Pathology and the Genome Center, University of California, Davis, CA 95616, U.S.A.; \\ ${ }^{4}$ Joint BioEnergy Institute and Physical Biosciences Division, Lawrence Berkeley National Laboratory, Berkeley, CA, 94720, \\ U.S.A.; and ${ }^{5}$ University Tübingen, 72076 Tübingen, Germany
}

Submitted 14 December 2014. Accepted 18 February 2016.

\begin{abstract}
Gram-negative bacteria continuously pinch off portions of their outer membrane, releasing membrane vesicles. These outer membrane vesicles (OMVs) are involved in multiple processes including cell-to-cell communication, biofilm formation, stress tolerance, horizontal gene transfer, and virulence. OMVs are also known modulators of the mammalian immune response. Despite the well-documented role of OMVs in mammalian-bacterial communication, their interaction with plants is not well studied. To examine whether OMVs of plant pathogens modulate the plant immune response, we purified OMVs from four different plant pathogens and used them to treat Arabidopsis thaliana. OMVs rapidly induced a reactive oxygen species burst, medium alkalinization, and defense gene expression in $A$. thaliana leaf discs, cell cultures, and seedlings, respectively. Western blot analysis revealed that EF-Tu is present in OMVs and that it serves as an elicitor of the plant immune response in this form. Our results further show that the immune coreceptors BAK1 and SOBIR1 mediate OMV perception and response. Taken together, our results demonstrate that plants can detect and respond to OMV-associated molecules by activation of their immune system, revealing a new facet of plant-bacterial interactions.
\end{abstract}

All gram-negative bacteria release membrane vesicles by pinching off their outer membrane (OM) (Kulp and Kuehn 2010). These spherical vesicles are continuously released under various growth conditions and represent a microcosm of the $\mathrm{OM}$ composition and encapsulated periplasmic content. OM

Current address for B. Schwessinger: The Australian National University, Research School of Biology, Acton ACT 2601, Australia.

Current address for A. Daudi: Bio-protocol, P.O. Box 61231, Palo Alto, CA 94306, U.S.A.

Current address for A. K. Jehle: Christian Doppler Laboratory for Monitoring of Microbial Contaminants, Institute for Milk Hygiene, Milk Technology and Food Science, University of Veterinary Medicine, Vienna, Austria.

Corresponding authors: O. Bahar; E-mail: ofirb@agri.gov.il; Telephone: +9723-9683561; Fax: +972-3-9604180; and P. C. Ronald; E-mail: pcronald@ ucdavis.edu; Telephone: +1.530 .752 .1654 ; Fax: +1.530 .752 .6088 .

*The $\boldsymbol{e}$-Xtra logo stands for "electronic extra" and indicates that five supplementary figures and one supplementary table are published online.

() 2016 The American Phytopathological Society vesicles (OMVs) contain membrane lipids, lipopolysaccharides (LPS), OM proteins, peptidoglycan (PGN), degradative enzymes, nucleic acids, virulence factors, and more (Kuehn and Kesty 2005). Rather than being a consequence of membrane instability, as previously speculated, OMV release has now been recognized as a unique, bona-fide secretion system for a wide range of molecules (McBroom et al. 2006).

The OMV secretory pathway differs from other secretion systems and provides several advantages. For example, proteins secreted via OMVs are protected from degradation by extracellular proteases and can persist longer and travel further distances. The release of OMVs also allows the bacterium to secrete a combination of molecules to be simultaneously released at a target location and at much higher concentration than via other export systems (Bonnington and Kuehn 2014). OMVs can specifically fuse to target cells (bacterial or mammalian) and undergo endocytosis, delivering the content of the vesicle into the host cell (Kadurugamuwa and Beveridge 1998; Kesty et al. 2004).

The wide range of secreted molecules and the unique features of this secretion system also provide bacteria with multiple capabilities. So far, OMVs have been shown to mediate cell-tocell communication (Mashburn and Whiteley 2005), deliver toxins and other virulence factors into host cells (Ellis and Kuehn 2010; Kadurugamuwa and Beveridge 1996), improve tolerance to various physiological stresses (MacDonald and Kuehn 2013), provide resistance to bacteriophage infection (Manning and Kuehn 2011), serve as a conduit for horizontal gene transfer (Renelli et al. 2004), and affect biofilm function (Schooling and Beveridge 2006).

OMVs carry several highly conserved microbial signatures, also termed microbe or pathogen-associated molecular patterns (MAMPs or PAMPS) such as LPS, PGN, flagellin, and other major surface proteins, which make them potent elicitors of host immune responses (Ellis and Kuehn 2010). These responses are mediated, at least in part, by known surface receptors termed pattern recognition receptors (PRRs). For example, toll-like receptor (TLR) 5 and TLR4, the mammalian receptors for flagellin and LPS, respectively, and TLR2 have been shown to mediate immune responses following OMV treatment (Ellis et al. 2010; Park et al. 2013). Although both the proteinaceous and the LPS cargo of OMVs have been shown to induce host immunity, LPS are regarded as the more potent inducer of the two (Ellis et al. 2010). The sensitivity of mammalian cells to LPS appears to be much higher than that of plant cells. While concentrations of $10 \mathrm{ng}$ or less per $5 \times 10^{4}$ cells is sufficient to induce immune 
responses in mammalian cells (Ellis et al. 2010), 5 to $50 \mu \mathrm{g}$ of LPS per milliliter is required to induce a response in Arabidopsis plants (Silipo et al. 2005; Zipfel and Felix 2005). Lower doses of LPS (in the range of $500 \mathrm{ng} / \mathrm{ml}$ ) have also been shown to be effective in triggering immune responses in Arabidopsis plants expressing a bulb-type lectin S-domain-1 receptor like-kinase (SD1-29) (Ranf et al. 2015).

Plant-induced immune responses are typically divided into two types. The first type of induced defense is mediated by surface PRRs that detect MAMPs at the extracellular milieu and is abbreviated as MTI or PTI for MAMP- or PAMP-triggered immunity (Zipfel 2014). In addition to the bulb-type lectin S-domain-type receptor, these receptors can also carry leucine-rich repeats (LRRs) motifs or lysin motifs (LysM) in the extracellular domain. Plant PRRs of the LRR type are closely related in both structure and function to mammalian TLRs (Ronald and Beutler 2010). The second type of induced defense is mediated by intracellular receptors of the nucleotide-binding site-LRR family, which recognize secreted pathogen effectors intracellularly. This type of immunity is often called effector-triggered immunity (Dodds and Rathjen 2010).

The two best-characterized plant PRRs are the Arabidopsis flagellin sensitive 2 (FLS2) receptor (Gómez-Gómez and Boller 2000) and the elongation factor receptor (EFR) (Zipfel et al. 2006). FLS2 recognizes bacterial flagellin (the major building block of flagellum) or its derivative peptide flg22. EFR recognizes elongation factor-thermo unstable (EF-Tu) (involved in bacterial translation) or its derivative peptide elf 18 .

Flagella are bacterial appendages that can be sheared off the cell surface by either mechanical force or actively by the bacterium (Tans-Kersten et al. 2001). They are, therefore, hypothesized to physically interact with the extracellular LRR domain of FLS2 (Sun et al. 2013). In contrast, EF-Tu is predicted to function in the bacterial cytoplasm and it is not fully understood how it reaches the apoplastic space of plant tissue, to interact with its cognate receptor EFR, other than by bacterial lysis. Other known pairs of PRRs and MAMPs are the LysM-containing receptors LYM1 and LYM3, which detect the cell-wall component PGN (Willmann et al. 2011) and chitin elicitor receptor kinase 1 and lysin-motif receptor kinase 5 (CERK1/LYK5) that binds the fungal cell-wall component chitin (Cao et al. 2014; Miya et al. 2007). Many of the known PRRs require a coreceptor for their activity. One of the most well-studied coreceptors is the brassinosteroid-insensitive 1-associated kinase (BAK1), which is known to associate with both FLS2 and EFR upon flg22 and elf18 binding, respectively (Schwessinger and Rathjen 2015) and is suspected to serve as a coreceptor for additional LRR-receptorlike kinases (RLKs) and LRR receptor-like proteins (RLPs). Another coreceptor is the RLK suppressor of BAK1-interacting receptor-like kinase 1 (SOBIR1), which has been shown to cooperate with several LRR-RLPs, such as the Arabidopsis ReMAX, SCFE1, and RBPG1 (Jehle et al. 2013a; Zhang et al. 2013, 2014) and the tomato $\mathrm{Cf}-4, \mathrm{Ve} 1$, and Eix2 proteins (Liebrand et al. 2013). Unlike RLKs, RLPs lack the intracellular kinase domain that serves as the signaling domain of the receptor and are, therefore, hypothesized to require SOBIR1 as a separate signaling component to mediate signal transduction (Liebrand et al. 2014).

Despite the well-documented role of OMVs in mammalian host-bacterial interactions, their role in plant-microbe interactions has not been well studied. Nevertheless, several studies on OMVs and their possible roles in plant-bacterial interactions have recently been reported. These include characterization of the OMV proteomes from Xanthomonas campestris pv. campestris (Sidhu et al. 2008) and Pseudomonas syringae pv. tomato T1 (Chowdhury and Jagannadham 2013), the contribution of OMVs to surface adherence of Xylella fastidiosa in grapes (Ionescu et al. 2014), and the role of OMVs in secreting plant cell wall-degrading enzymes (Solé et al. 2015). To the best of our knowledge, the effect of OMVs on plant immunity has not yet been examined. We previously reported on the association of a X. oryzae pv. oryzae OM protein (PXO_03968, formerly known as Ax21) with OMVs (Bahar et al. 2014), but no functional characterization of the vesicles has been undertaken.

Here, we demonstrate that Arabidopsis thaliana plants can sense and respond to bacterial OMVs by activating known innate immune responses. We also show that EF-Tu is present in secreted OMVs and that it serves as an inducer of plant immunity in this form. Our genetic analyses indicate that EFR is not the only receptor that mediates the immune response to OMVs but that other PRRs are also involved. Collectively, our results reveal a new dimension of the complex and fascinating dialog between plants and microbes.

\section{RESULTS}

OMVs are released by plant-pathogenic bacteria.

Both $X$. campestris pv. campestris and $X$. oryzae pv. oryzae release OMVs when grown in either rich or minimal media. High-speed centrifugation of cell-free supernatants resulted in the appearance of a translucent yellow pellet, originating from the membrane-bound pigment xanthomonadin, which is characteristic of most plant-pathogenic Xanthomonas species (Fig. 1A). OMV yield differed with respect to the growth media used. Peptone sucrose broth and M9 media (Sambrook et al. 1989) yielded the highest amount of OMVs (an average of $50 \mu \mathrm{g}$ per $10^{11} \mathrm{CFU}$ ) compared with yeast extract broth (YEB) (Bahar et al. 2014) (Fig. 1A) and XVM2 media (Wengelnik et al. 1996) (Supplementary Fig. S1), which produced approximately five- to10-fold less. Density step-gradient centrifugation coupled with Western blot analysis, using the OMV-associated protein PXO_03968 as a marker (Bahar et al. 2014), revealed that most vesicles migrate to the 25 to $30 \%$ density fraction (Fig. 1B). Further analysis of these fractions by transmission electron microscopy (TEM) showed that the size of the vesicles vary from as small as $20 \mathrm{~nm}$ to as large as $200 \mathrm{~nm}$ in diameter (Fig. 1C and D). Bacterial outer cellular appendages such as flagella or pili that occasionally contaminate OMV preparations were not observed in TEM images.

\section{Arabidopsis thaliana respond to OMVs by activating defense-gene expression.}

To examine whether $X$. campestris pv. campestris OMVs induce immune responses in Arabidopsis, we first assessed the induction of defense-related gene expression in response to OMV treatment using quantitative real-time polymerase chain reaction (qRT-PCR). Col-0 seedlings were incubated with purified OMVs from $X$. campestris pv. campestris and the induction of known defense-related marker genes was examined. In a timecourse experiment, both marker genes, flg22-induced receptorlike kinase 1 (FRK1) (At2g19190) and At5g57220 (Schwessinger et al. 2011), were highly induced in response to OMV treatment (Fig. 2A). FRK1 expression levels gradually rose from $30 \mathrm{~min}$ to $24 \mathrm{~h}$ postinduction, whereas At5g57220 levels peaked at $2 \mathrm{~h}$ and, then, started dropping (Fig. 2A). Using a dilution response curve, we measured significant activity in OMV preparations even when diluted 20-fold from the original preparation (corresponding to a final concentration of approximately $1.5 \mu \mathrm{g}$ of OMV per milliliter) (Fig. 2B).

OMVs induce typical immune responses in Arabidopsis.

To further examine the immune responses activated by OMVs, we performed a reactive oxygen species (ROS) burst assay. We treated Col-0 wild-type (WT) leaf discs with purified OMVs from $X$. campestris pv. campestris and elf 18 or water as controls. A typical ROS burst was observed in response to 
OMVs and elf18 (Fig. 3A). No ROS burst was observed in the mock treatment or when the OMV preparation was boiled.

To test whether the observed ROS burst is mediated through the PRR EFR, we performed a similar assay using the efr-l mutant line, which is not capable of detecting EF-Tu. In two independent experiments, the efr- 1 mutant line was insensitive to OMVs (Fig. 3B). To examine the presence of EF-Tu in OMVs, we performed Western blot analysis using an EFTu-specific antibody. We detected EF-Tu in both $X$. oryzae pv. oryzae cell-free supernatants and in the OMV fraction (Supplementary Fig. S2). These results suggest that EF-Tu is present in OMVs and that the observed ROS burst is mediated by EFR. Nevertheless, when we tested the efr-1 mutant line with the marker gene expression assay as above, EFR appeared to be dispensable for OMV response, as both marker genes were activated to a similar level as that of Col-0 (Fig. 3C). To address the discrepancy between the two assays, we used a third assay, measuring cell culture medium alkalinization (Kunze et al. 2004) in response to OMVs. Two available cell culture lines were tested with this assay, Ler-0 WT and a Col-0 efr bakl double mutant line. A small and reproducible dose-dependent increase in the extracellular $\mathrm{pH}$ of OMV-treated cultures was observed in both the Ler-0 WT and Col-0 bakl efr double mutant line (Supplementary Fig. S3). Together, these results suggest that EF-Tu is present in OMVs and can be sensed by the
Arabidopsis EFR when in this form. Nevertheless, gene expression and medium alkalinization assays suggest EF-Tu is not the sole immune elicitor carried by OMVs.

\section{Arabidopsis PRR mutant lines retain responsiveness to OMVs.}

In an attempt to determine what other plant receptors may participate in OMV perception and response, we took a genetic approach and tested a series of Arabidopsis PRR mutant lines using the marker gene expression assay.

Bacterial flagella are outer cellular appendages that occasionally contaminate OMV preparations (Sidhu et al. 2008). Flagellin, the major protein building block of flagella, is a known inducer of plant immunity. Therefore, although we did not observe flagella in our TEM analysis, we sought to examine whether the Arabidopsis response to OMVs is mediated by the FLS2 receptor that senses flagellin. We used an Arabidopsis fls2 efr mutant line that lacks both FLS2 and EFR as well as the WT Col-0 genotype. As observed for the efr- 1 mutant, the $f l s 2$ efr double mutant line still expresses the marker genes At5g57220 and FRK1 in response to OMV treatment (Fig. 4A). These results suggest that other MAMPs in addition to EF-Tu and flagellin are present in OMVs.

A newly discovered plant immune receptor is the Arabidopsis RLP ReMAX, which responds to the yet-unidentified Xanthomonas
A
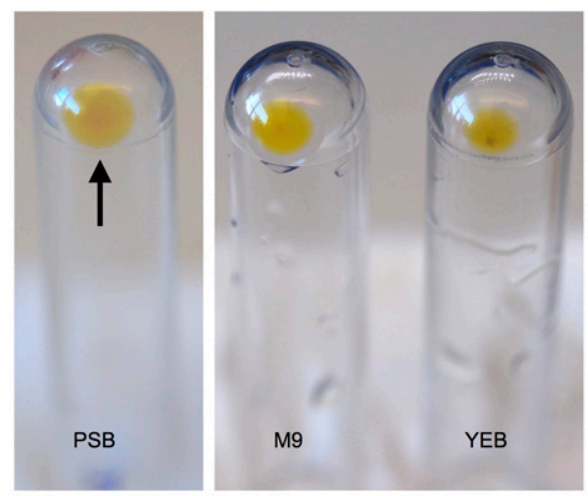

C

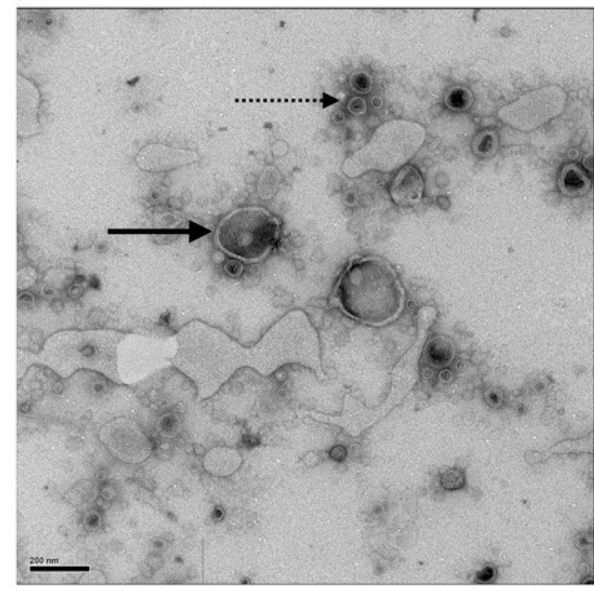

B

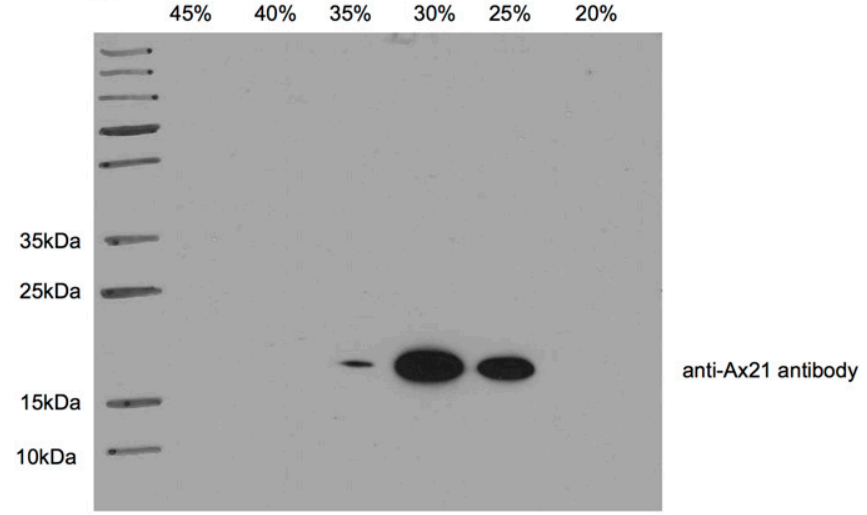

D

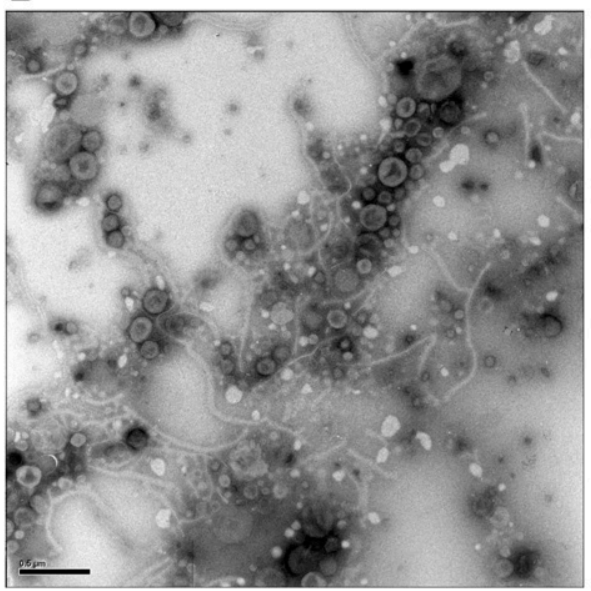

Fig. 1. Preparation of outer membrane vesicles (OMVs) from Xanthomonas campestris pv. campestris 33913 and X. oryzae pv. oryzae PXO99. A, The yellowpigmented pellet (arrow) of OMVs seen after ultracentrifugation of Xanthomonas cell-free supernatants from peptone sucrose broth, M9, and YEB media (Bahar et al. 2014). B, Western blot analysis following Optiprep density step-gradient centrifugation, using an OMV-associated protein (PXO_03968, formerly Ax21) antibody to identify the OMV-containing fraction. C, Transmission electron microscopy (TEM) of purified OMVs from X. campestris pv. campestris. The solid line arrow points to a large (approximately $200 \mathrm{~nm}$ diameter) vesicle and a dashed line arrow points to a group of smaller (approximately 30 to 70 nm) vesicles. Size bar is $200 \mathrm{~nm}$. D, TEM of OMVs purified from X. oryzae pv. oryzae following density step-gradient centrifugation (from $30 \%$ lane in B). Size bar is $500 \mathrm{~nm}$. 
MAMP eMAX (Jehle et al. 2013b). To examine the possible involvement of ReMAX in Arabidopsis response to OMVs, we treated the triple mutant line fls 2 efr rlpl-2 (Jehle et al. 2013a), insensitive to flagellin, EF-Tu, and eMAX, with OMVs, and compared the level of defense-gene expression to WT Col-0 and the efr-1 mutant line. The triple mutant line was still fully responsive to OMV treatment. The observed marker gene expression levels were similar to those observed in Col-0 or the efr-1 mutant treated with OMVs (Fig. 4B).

Arabidopsis mutants lacking the peptidoglycan receptors LYM1 and LYM3 maintain response to OMVs.

Because we did not observe significant reduction in Arabidopsis marker gene expression in response to OMVs with any of the proteinaceous MAMP receptor mutants that we tested, we sought to examine the possible involvement of peptidoglycan (a component of the bacterial cell wall) as a potential OMVborne MAMP. Because OMV blebbing results in entrapment of periplasmic fluid, OMVs also contain peptidoglycan molecules (Kaparakis et al. 2010). We, therefore, used Arabidopsis mutant lines lacking the LysM domain-containing peptidoglycan receptors LYM1 and LYM3. Both mutants responded in similar amplitude compared with Col-0 (Fig. 4C and D), indicating that the absence of the peptidoglycan receptors does not lead to OMV insensitivity.

\section{The Arabidopsis immune coreceptors BAK1 and SOBIR1 mediate OMV response.}

Many of the known PRRs cooperate with other membranebound coreceptors to mediate downstream signaling following ligand perception. To test whether such central components of plant immune signaling are involved in OMV perception and
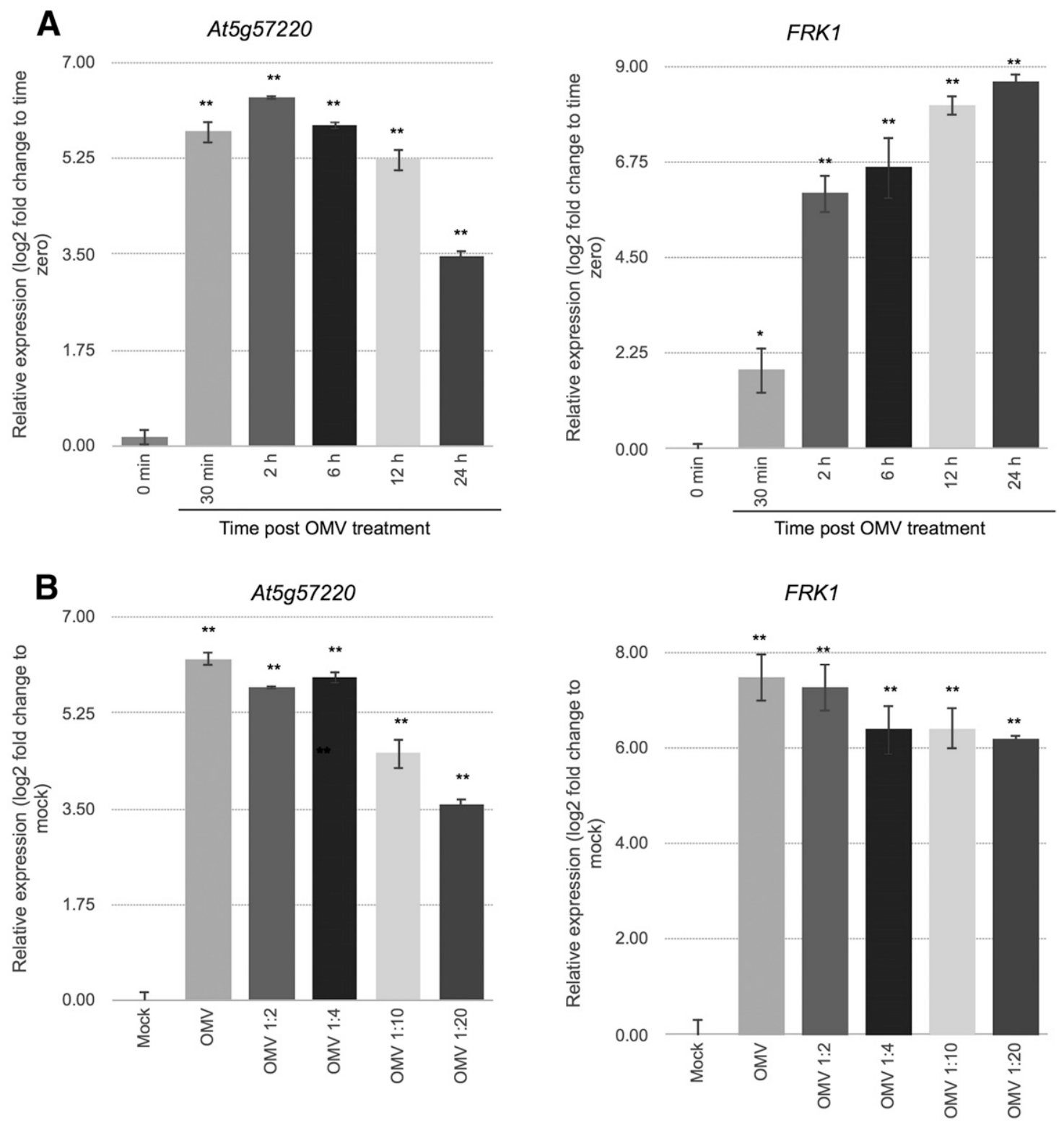

Fig. 2. A time course and a dilution response curve of Arabidopsis Col-0 seedlings to outer membrane vesicle (OMV) treatment. A, Arabidopsis seedlings were treated with Xanthomonas campestris pv. campestris OMVs and were then harvested for RNA extraction, cDNA synthesis, and quantitative real-time polymerase chain reaction (qRT-PCR) analysis at several timepoints. The activation of two defense marker genes (At5g57220 and $F R K 1)$ was examined. Each timepoint is an average of three independent biological replicates consisting of two seedlings each. B, Arabidopsis seedlings were treated with different dilutions of $X$. campestris pv. campestris OMVs (from 30 to $1.5 \mu \mathrm{g} / \mathrm{ml}$ ) and were harvested $6 \mathrm{~h}$ postinduction for qRT-PCR analysis, as above. Error bars represent standard error and one asterisk (*) indicates significant difference at $P<0.05$ and two asterisks $(* *)$ at $P<0.01$, compared with time zero (A) or mock treatment (B) using Dunnet's test. These experiments were carried out once. 

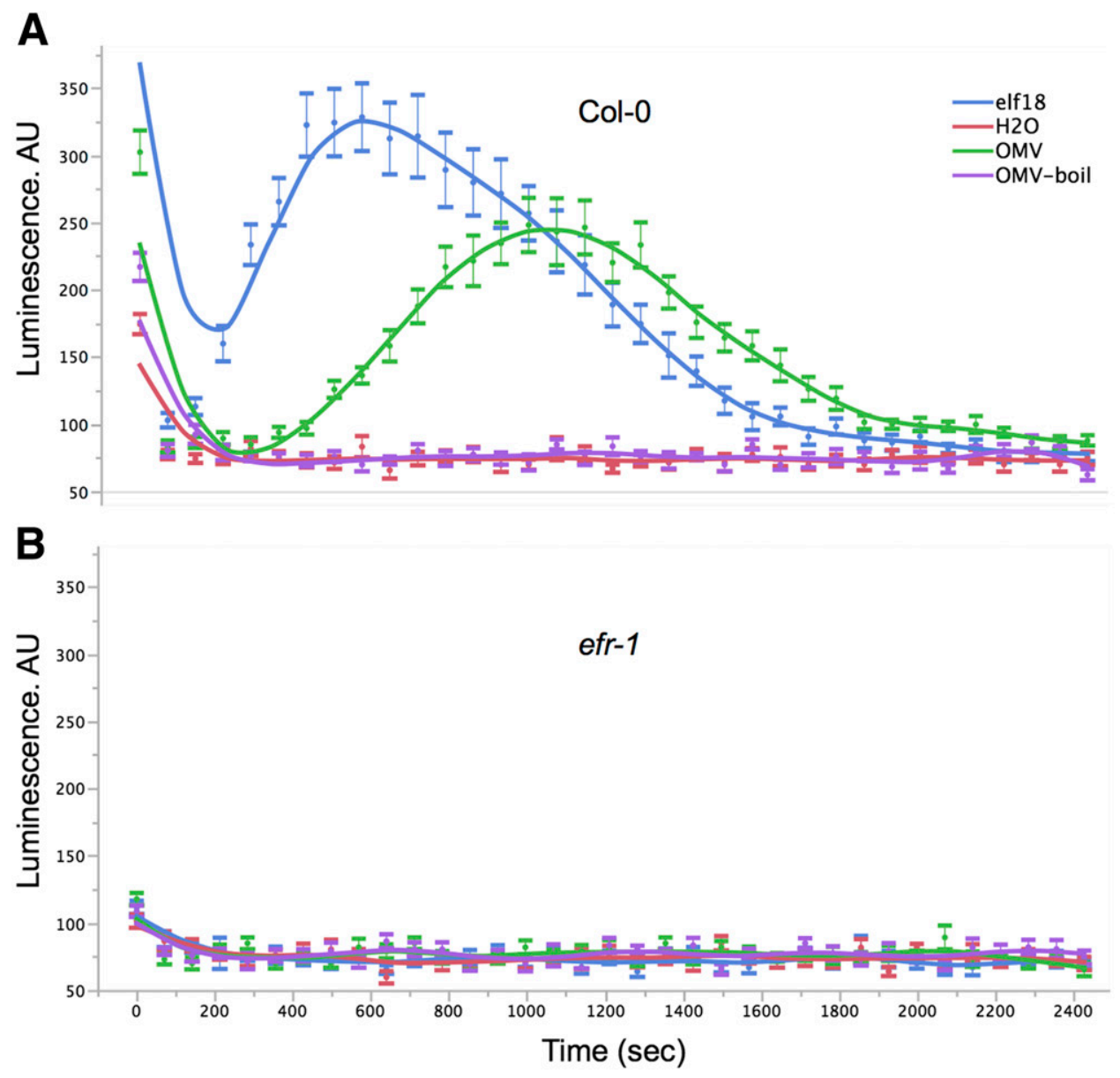

C

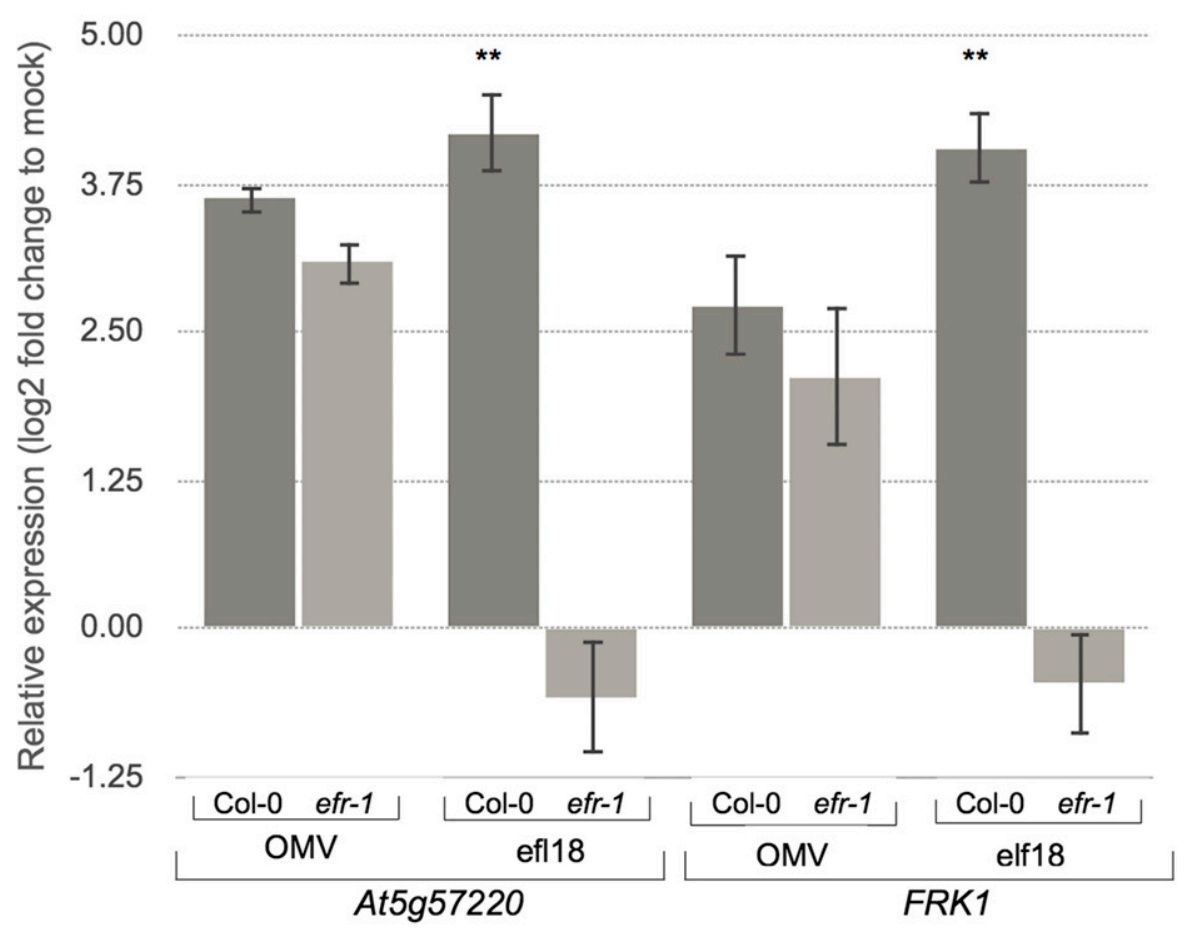

Fig. 3. Outer membrane vesicles (OMVs) induce reactive oxygen species (ROS) and defense gene expression. A, Leaf discs of Col- 0 and $\mathbf{B}$, $e f r-1$ mutant line were treated with $30 \mu \mathrm{g}$ of OMV per milliliter (or boiled OMVs) purified from Xanthomonas campestris pv. campestris, elf 18 (100 nM), or water, and luminescence was scored over time. Each timepoint represents an average of 12 biological replicates. Standard error bars are shown. C, Seedlings of Col- 0 and $e f r-1$ mutant lines were treated with OMVs, elf18 $(1 \mu \mathrm{M})$, and water, and the response of defense-related marker genes was determined $6 \mathrm{~h}$ postchallenge. Gene expression in response to OMV and elf 18 was normalized to mock treatment. In response to OMV treatment, Col- 0 and $e f r-1$ were not statistically different $(P<0.05)$ between them; however, they were both significantly $(P<0.01)$ higher relative to their mock treatments. Statistical differences are indicated with asterisks $(* *, P<0.01)$ in response to elf 18 treatment. Error bars represent standard error. ROS assays were performed twice and gene expression assays were performed three times, all showing similar results. 
signaling, we used the Arabidopsis mutant lines bakl-5 and sobir1-12, which do not express a functional version of the coreceptors BAK1 and SOBIR1, respectively. We used qRTPCR analysis to compare the response of the mutant lines to that of Col-0. A statistically significant $(P<0.05)$ reduction in the induction of marker genes At5g57220 and FRK1 was observed with the bak1-5 mutant line (Fig. 4E). A similar trend was observed with the sobirl-12 mutant line, in which the expression of both genes was statistically lower than that of Col-0 WT (Fig. 4F). In second and third repeats of this experiment, only one of the two genes (one in each experiment) had lower expression levels when compared with Col-0 WT (Supplementary Fig. S4). Collectively, these results suggest that multiple elicitors are carried by OMVs and that the immune coreceptors BAK1 and SOBIR1 are involved in OMV perception and downstream signaling.

\section{OMVs of multiple plant pathogens}

induce defense-gene expression in Arabidopsis.

To test whether the immunogenic activity of OMVs is conserved among different plant pathogens, we purified OMVs from
$X$. oryzae pv. oryzae, a bacterial pathogen of rice, $P$. syringae pv. tomato DC3000, a bacterial pathogen of Arabidopsis, and Acidovorax citrulli, a bacterial pathogen of cucurbits (Bahar and Burdman 2010). To compare the protein cargo of vesicles of different origin, $20 \mu \mathrm{l}$ of each OMV preparation were loaded onto sodium dodecyl sulfate-polyacrylamide gel electrophoresis (SDS-PAGE), followed by Coomassie blue staining. Protein concentration and profile varied among the bacterial strains tested (Supplementary Fig. S5A). Most notably, P. syringae pv. tomato DC3000 releases large amounts of OMVs, as reflected in the presence of a very large (and clear-colored) pellet, but this fraction contained very little protein. Statistically significant induction of defense-gene expression was observed with OMVs from all three bacterial strains. The level of defense-gene activation by $X$. oryzae pv. oryzae and Acidovorax citrulli was similar to that of $X$. campestris pv. campestris, while that of $P$. syringae pv. tomato was more modest, yet still significant $(P<0.05)$. These results indicate that OMVs from diverse bacterial species carry inducers of Arabidopsis immunity, suggesting that activation of plant immunity by OMVs is a widespread phenomenon that is also independent of plant-pathogen compatibility.
A

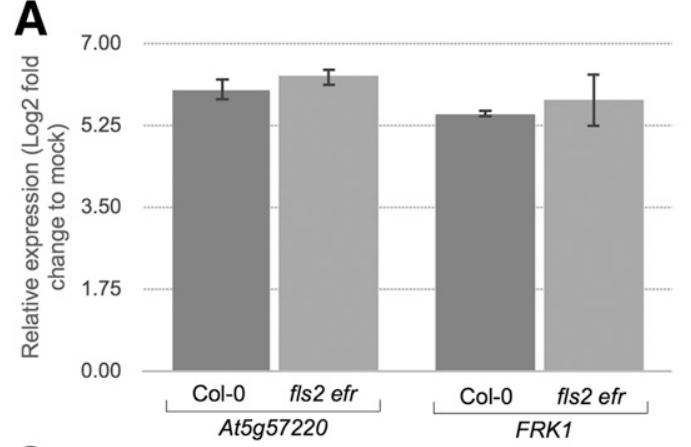

C
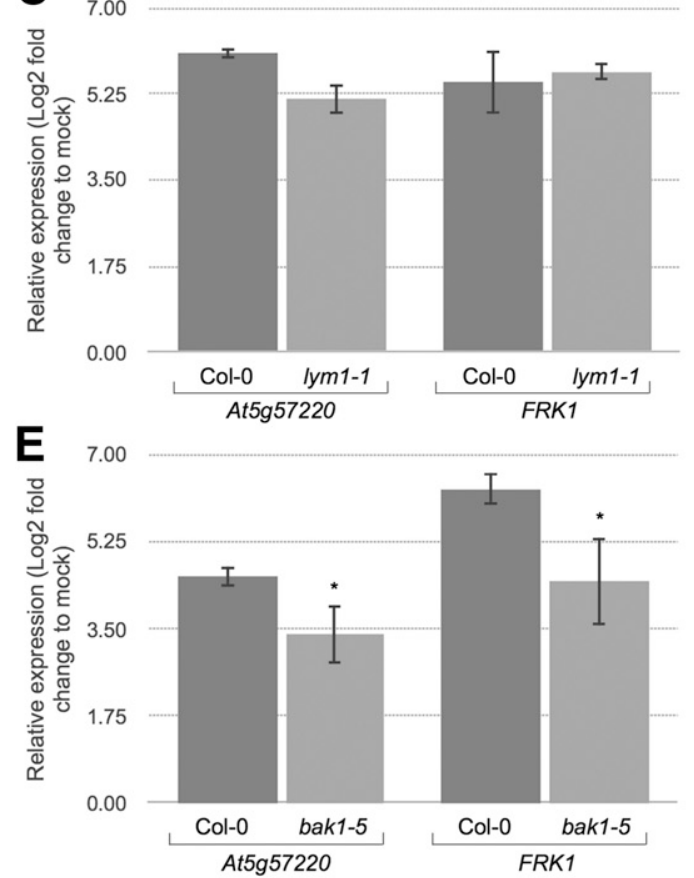

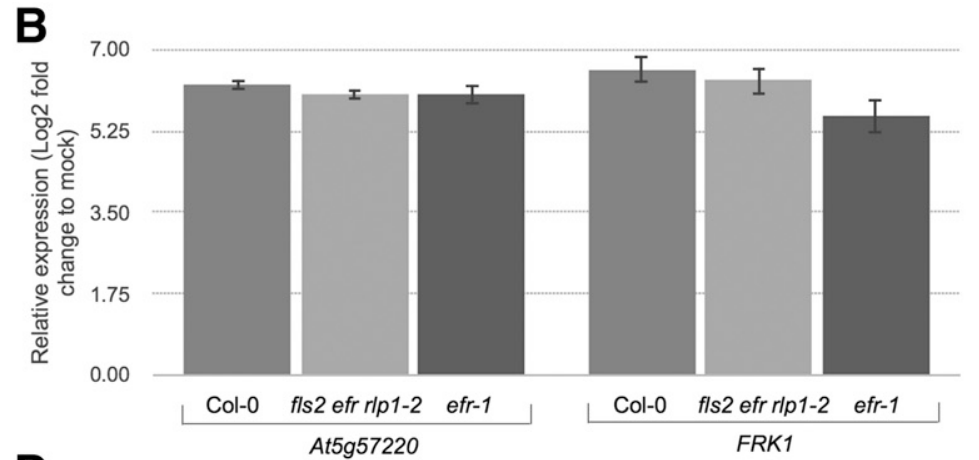

D
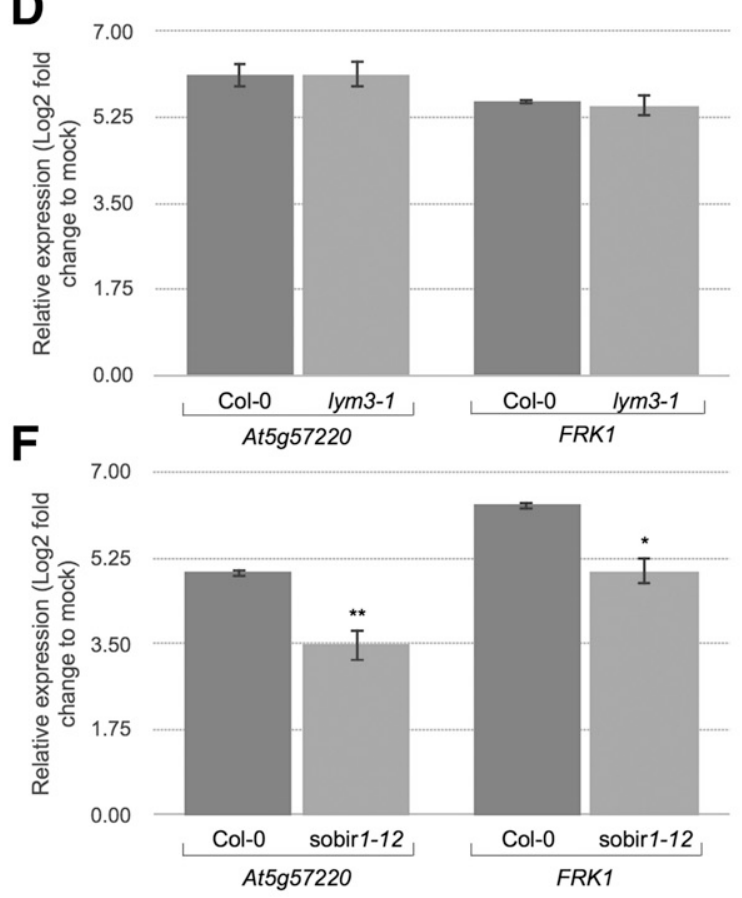

Fig. 4. Involvement of Arabidopsis innate immune receptors in the response to outer membrane vesicles (OMVs). Defense-related marker gene expression was determined in A, fls2 efr, B, fls2 efr rlp1-2, C, lym1-1, D, lym3-1, E, bak1-5, and F, sobir1-12 mutant lines. Expression levels were recorded 6 h post-OMV treatment and were normalized to mock. All tested lines had significantly higher $(P<0.05)$ gene expression level compared with mock. Each mutant line was then compared with Col-0, using either $t$ test (A, C through F) or Dunnet's test (B). Error bars represent standard error and one asterisk (*) indicates significant difference at $P<0.05$ and two asterisks $(* *)$ at $P<0.01$ between genotypes. Each treatment included at least three biological replicates. Experiments represented in $\mathrm{A}$ to $\mathrm{C}$ and $\mathrm{E}$ were conducted at least twice, showing similar results, experiments represented in $\mathrm{F}$ (sobir1-12) were performed three times, and experiments represented in $\mathrm{D}$ were conducted once. 


\section{Proteinase and heat treatments}

\section{did not abolish defense-gene activation.}

In an attempt to narrow down the nature of the one or more immune inducers carried by OMVs, we treated OMVs with proteinase K or boiling, two treatments that have previously been used to determine the molecular nature of immune elicitors (Jehle et al. 2013b; Kunze et al. 2004). In two independent experiments, neither boiling nor proteinase $\mathrm{K}$ treatment reduced the level of OMV activity but, rather, slightly enhanced it (Supplementary Fig. S6). While this result may suggest that at least part of the immunogenic activity of OMVs could result from nonproteinaceous inducers, it is also possible that the peptides resulting from the proteinase $\mathrm{K}$ digest or proteinase $\mathrm{K}$ itself could induce immune response. To address this possibility, we repeated this experiment and conducted three rounds of centrifugation $(150,000 \times g$, $60 \mathrm{~min}$ ) and washing steps to discard digested proteins and proteinase $\mathrm{K}$. We noticed that the proteinase $\mathrm{K}$-treated OMVs still had higher activity than nontreated OMVs with both marker genes (Fig. 5). The supernatant control collected at the final wash was not statistically different than mock treatment, indicating that possible immunogenic peptides (and proteinase $\mathrm{K}$ ) remaining after the digest were successfully removed. Proteinase $\mathrm{K}$ itself, on the other hand, appeared to be very immunogenic; nevertheless, boiling completely abolished its immunogenic activity (Fig. 5). Altogether, these results show that OMV remain or even become more immunogenic after proteinase $\mathrm{K}$ treatment.

\section{DISCUSSION}

OMV release by gram-negative bacteria is a process occurring at all stages and forms of the bacterial life cycle (Kaparakis-

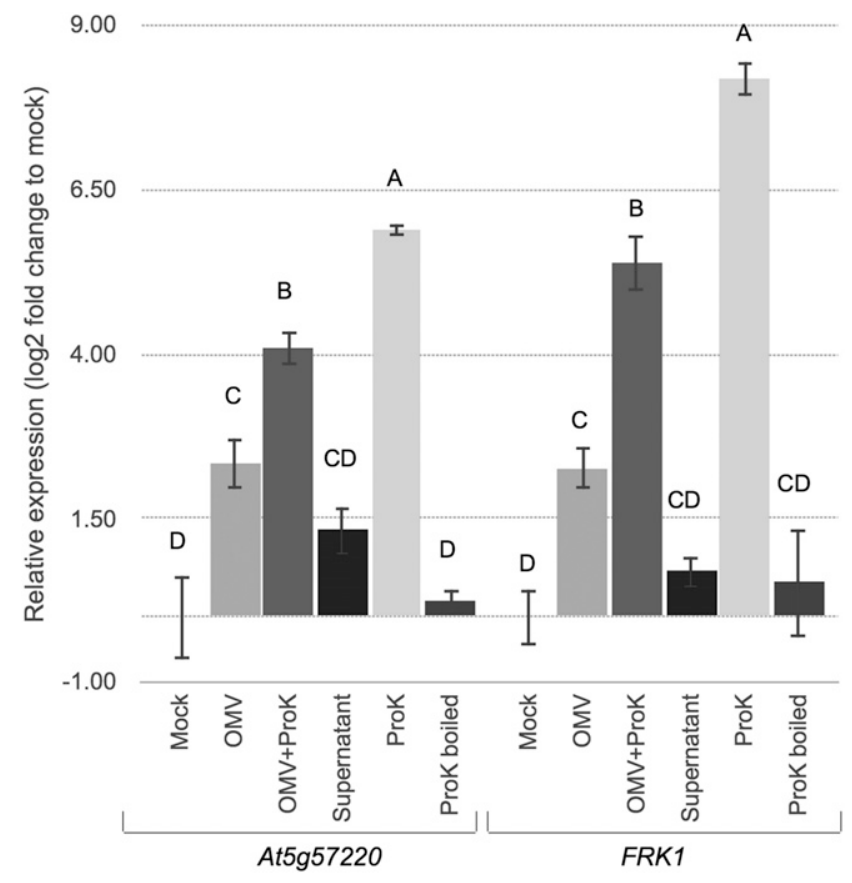

Fig. 5. Proteinase $\mathrm{K}$ treatment does not abolish outer membrane vesicle (OMV) immunogenic activity. Col-0 seedlings were treated with water (Mock), OMVs (OMV), OMV-treated with proteinase K (OMV+ProK), supernatant of final OMV wash after proteinase K treatment (supernatant), proteinase $\mathrm{K}$ alone (ProK), and heat-inactivated proteinase K (ProK boiled) treatment. Error bars represent standard error and different letters indicate significant differences $(P<0.05)$ among treatments using Tukey-Kramer honestly significant difference test. Each treatment included three biological replicates and the experiment was performed twice, using two different OMV preparations. Similar results were observed between the two experiments.
Liaskos and Ferrero 2015). OMVs carry diverse molecules and participate in multiple biological processes, including pathogenesis. Despite the key role that OMVs play in the bacterial life cycle, the interaction of these vesicles with plants is not well characterized.

In this study, we addressed the question of whether plants recognize and respond to OMVs. We assayed three defense responses (defense gene activation, ROS burst, and medium alkalinization) in Arabidopsis in response to OMV treatment. In all three assays, a clear immune response was observed with Arabidopsis WT lines in response to OMV treatment, indicating that bacterial OMVs are immunogenic to Arabidopsis plants. Considering the fact that OMVs are long-known immunogenic factors of mammalian host cells (Ellis and Kuehn 2010), these results are not surprising, yet they are the first demonstration that OMVs modulate the plant immune response.

In our ROS burst assays, the response to OMVs was slightly delayed compared with the response to elf 18 treatment, peaking at approximately $15 \mathrm{~min}$ versus approximately 7 min postchallenge, respectively. When comparing our results with published data in which ROS burst was measured in response to purified MAMPs and live bacteria (Smith and Heese 2014), a positive correlation can be observed between the level of purity of the inducing agent and time required to reach response peak. Specifically, Smith and Heese (2014) show that the response to flg22 peaks at approximately $10 \mathrm{~min}$ postinduction (similar to what we observed with elf18) and the response to live bacteria (DC3000) peaks at approximately 35 min postchallenge, suggesting that the purer the inducing agent is the quicker the response peak is. This could also be due, at least in part, to substances that chemically quench the ROS burst or to factors that suppress MTI, such as LPS, that may be present in OMVs and live bacteria (Aslam et al. 2008; Newman et al. 2007; Tellström et al. 2007).

We observed that the ROS burst in Arabidopsis in response to OMV treatment was dependent on the presence of EFR. This led us to hypothesize and, subsequently, verify that EF-Tu is present in OMVs. This observation is supported by proteomic studies of OMVs of X. campestris pv. campestris B100 (Sidhu et al. 2008) and of the human pathogen Haemophilus influenza 86-028NP (Sharpe et al. 2011), which have identified EF-Tu in the OMV proteome. It has long been debated how the cytosolic MAMP EF-Tu interacts with the plant EFR receptor (Zipfel et al. 2006). Our results demonstrate that EF-Tu is present in OMVs and that it can induce plant immunity in this form. It is an intriguing question how and why a presumed cytosolic protein such as EF-Tu reaches OMVs. EF-Tu is not exceptional in this regard, as other cytosolic components, such as DNA molecules, have been associated with OMVs. One possible explanation for the presence of cytosolic content in OMVs is the formation of a newly described type of membrane vesicle that blebs from inside the bacterial cell and entraps cytosolic content and inner membrane (Pérez-Cruz et al. 2013). In comparison with the single-bilayer OMVs, these vesicles are composed of a double-bilayer structure and were shown to carry cytosolic content including DNA molecules. Based on this theory, EF-Tu should be entrapped inside the vesicle lumen. If that is, indeed, the case, how does it become available to the plant surface receptor EFR? This question still remains unanswered, but it could explain the delayed ROS response to OMVs compared with purified elf18.

In contrast to the ROS burst assays, in gene expression and medium alkalinization assays, we found that the absence of EFR does not lead to loss of sensitivity to OMVs (i.e., efr-1 mutant line responds to OMV similarly to WT). Additionally, while OMV boiling abolished the ROS burst, it did not reduce defense-gene expression. The discrepancy between the results of the different assays is not surprising, as previous works have 
also noticed counterintuitive results when using different assays. For example, Smith and Heese reported that Arabidopsis ROS burst in response to live bacteria is completely dependent on the presence of the FLS2 receptor (e.g., no ROS burst with the fls 2 mutant line) (Smith and Heese 2014). Jehle et al. (2013a), on the other hand, have shown that medium alkalinization in Arabidopsis cell cultures in response to live bacteria can occur in the absence of FLS2 and EFR. These results indicate that the immune output in different assays may depend on different PRR-MAMP pairs. There are several possible explanations to why different immune outputs yield different results. First, it may be that the gene expression and medium alkalinization assays are more sensitive than the ROS burst assay and, therefore, other perhaps less potent MAMPs that are present in OMVs can still induce a response while, in ROS burst assays, they are below detection or response threshold. A second possible explanation is the difference in plant age and growth conditions between the different assays. While ROS assays use leaf discs of mature plants grown in soil media, the gene expression and medium alkalinization assays use 10day-old seedlings grown in liquid media or cell cultures, respectively. A third possibility is the different plant tissue used. While in the ROS burst assay, the tissue that is being exposed to OMVs is the leaf apoplast, in gene expression assays, it is primarily the roots, which are immersed in water and, in medium alkalinization, it is resuspended cell culture. Therefore, it is conceivable that OMVs carry other MAMPs in addition to EF-Tu but their recognition is not detectable in the ROS burst assay.

Consistently, double-knockout line fls 2 efr and the tripleknockout line fls 2 efr rlpl-2 lacking the ability to perceive flagellin, EF-Tu, and the yet unidentified MAMP eMax still respond to OMVs. It even further suggests that the Arabidopsis immune modulation by OMVs is either not mediated by FLS2 and ReMAX or that the response mediated by these receptors is masked by other participating receptors and their respective MAMPs.

Although all the LRR-type PRR mutant lines we tested (efr-1, fls2, fls2 efr, and fls2 efr rlp1-2) expressed defense marker genes in response to OMV treatment, mutations in the shared coreceptors BAK1 and SOBIR1 significantly decreased the level of defense-gene activation compared with WT Col-0 seedlings. These results suggest that these coreceptors are critical for perception of OMVs. BAK1 has a central role in mediating plant immune response via interaction with multiple LRR-RLKs and LRR-RLPs. SOBIR1 has also been shown to interact with and mediate signal transduction of multiple receptors, but of the LRR-RLP type (Liebrand et al. 2014). It is, therefore, logical to speculate that the reduced response of mutant lines impaired in these receptors is due to impairment of multiple PRR perception and signaling pathways. Collectively, these results support the notion that OMVs carry multiple MAMPs, which trigger plant immunity via multiple receptors of both RLK and RLP types.

In addition to EF-Tu and other proteinaceous MAMPs that may be present in OMVs, nonproteinaceous elicitors such as LPS, PGN, and nucleic acids have been shown to associate with OMVs (Kuehn and Kesty 2005). In contrast to the observation that these nonproteinaceous elicitors trigger mammalian immune responses (Kaparakis-Liaskos and Ferrero 2015), we found that Arabidopsis mutant lines lacking the LysM-containing receptors LYM1 or LYM3, which recognize PGN (Willmann et al. 2011), remain responsive to OMVs. These results suggest that either PGN does not serve as an active MAMP in this form or that the effect of OMV-carried PGN is masked by other MAMPs. To further investigate the nature of the MAMPs present in OMVs, we boiled or protease-treated OMVs. We found that these treatments did not abolish defense-gene activation but, rather, enhanced it. This result may indicate that the nonproteinaceous cargo (e.g., LPS, PGN) of OMV is, indeed, active. However, while protease treatment is expected to abolish the activity of a proteinaceous MAMP (Jehle et al. 2013b; Kunze et al. 2004), we cannot rule out the possibility that some of the MAMPs present in OMVs were not fully digested upon proteinase $\mathrm{K}$ treatment and remained active.

Considering the contribution of OMVs to pathogenesis of mammalian pathogens (Ellis and Kuehn 2010) and its importance for bacterial life style (MacDonald and Kuehn 2012), it is consistent to speculate that plant pathogens are no exception and that OMVs are released in planta to benefit the microbe. Supporting evidence comes from two recent reports that link OMV release to bacterial pathogenesis in plants (Ionescu et al. 2014; Solé et al. 2015). We further hypothesize that many of the roles attributed to OMVs of mammalian pathogens are also relevant to plant bacterial pathogens, such as biofilm formation, delivery of degrading enzymes and toxins, and quenching of antimicrobial compounds. An intriguing aspect in this regard is the ability of OMVs to fuse to host cells and deliver pathogenesisderived molecules directly into the host cell (Bomberger et al. 2009; Jäger et al. 2014). Whether this type of microbial delivery also exists in plant-OMV interactions remains an open question.

In addition to promoting pathogenesis, OMVs carry conserved microbial features (MAMPs) and, therefore, may betray the pathogen by activating host immune responses. In this study, we sought to examine whether the plant's surveillance system can detect OMVs and subsequently activate typical immune responses. We found that OMVs can indeed serve as modulators of the plant immune system and also demonstrated that EF-Tu serves as an active MAMP in its OMV form. The Arabidopsis mutant screen further suggests that OMVs carry multiple active MAMPs that can be sensed by both LRR-RLKs and RLPs. Further studies are underway to explore the full spectrum of interactions between bacterial OMVs and plants.

\section{MATERIALS AND METHODS}

\section{Bacterial strains and growth conditions.}

The strains used in this study are $X$. campestris pv. campestris 33913, X. oryzae pv. oryzae $\mathrm{PXO} 99, P$. syringae pv. tomato DC3000, and Acidovorax citrulli M6 (Bahar et al. 2009). Media used for bacterial cultures were i) peptone sucrose agar or broth, ii) YEB (Bahar et al. 2014), iii) M9 minimal media (Sambrook et al. 1989) containing $1.5 \%$ glucose and $0.3 \%$ casamino acids, and iv) XVM2 media (Wengelnik et al. 1996). Xanthomonas cultures were supplemented with $10 \mu \mathrm{g}$ of cephalexin per milliliter. All cultures were grown at $28^{\circ} \mathrm{C}$, shaking at $200 \mathrm{rpm}$ for the indicated time.

\section{Plant material.}

The Arabidopsis WT Col-0 line was used in this study as well as the previously described mutant lines in Col-0 background, i.e., efr-1 (SALK_044334) (Zipfel et al. 2006), fls2 (SALK_062054), fls2 efr (Nekrasov et al. 2009), lym1-1 and lym3-1 (GABI_419G07 and SALK_111212, respectively) (Willmann et al. 2011), sobirl-12 (SALK_050715) (Gao et al. 2009), bakl-5 (Schwessinger et al. 2011), and the triple mutant fls2 efr rlpl-2 (Jehle et al. 2013a). All mutant lines were verified by genotyping, using the primers listed in Supplementary Table S1. Arabidopsis seeds were surface-sterilized with $10 \%$ bleach, $1 \%$ Triton $\mathrm{X}-100$, and $70 \%$ ethanol, and were subsequently placed on a petri dish containing Murashige Skoog (MS) media with vitamins (Caisson Labs) solidified with $0.7 \%$ phytagel (Sigma). Seedlings were vernalized in the dark for 4 to 5 days at $4{ }^{\circ} \mathrm{C}$ and were then moved to a growth chamber with a 16-h photoperiod 
at $25^{\circ} \mathrm{C}$ for 5 to 7 days. Emerging seedlings were transferred into 24-well plates, two seedlings per well, containing $1 \mathrm{ml}$ of liquid MS media with vitamins and $1 \%$ sucrose for another 7 to 10 days, before the assay commenced. For ROS burst assays, plants were grown in commercial Sunshine mix \#1 soil under a short day regime (8-h photoperiod) for approximately four to five weeks.

\section{OMV purification.}

OMVs were purified according to Chutkan et al. (2013) with few modifications. Bacterial cultures were grown in 2-liter flasks containing $500 \mathrm{ml}$ of the indicated medium until an optical drensity at $600 \mathrm{~nm}$ of 0.4 to 0.6 . Cells were then pelleted at $9,000 \times g$ for $20 \mathrm{~min}$ and the supernatant was collected and passed through a $0.45-\mu \mathrm{m}$ filter (Nalgene). The cell-free supernatant was then spun down at $31,000 \times g$ for $2 \mathrm{~h}$ to pellet down the OMV fraction, and the supernatant containing other small molecules was discarded. The resulting pellet was then resuspended in $6 \mathrm{ml}$ of water and was ultracentrifuged for $2 \mathrm{~h}$ at approximately $170,000 \times g$. The final pellet was thoroughly resuspended in $1 \mathrm{ml}$ of water, was filtered through a syringe-mounted $0.22-\mu \mathrm{M}$ filter, and was stored at $4^{\circ} \mathrm{C}$ for further use. To examine the sterility of the preparation, a $10-\mu l$ drop was placed on peptone sucrose agar media, was incubated at $28^{\circ} \mathrm{C}$ for 5 days, and was inspected for contamination. For highly purified OMVs, we used Optiprep density step-gradient centrifugation as described by Chutkan et al. (2013). One-milliliter layers of diluted (20 to 45\%) Optiprep (Sigma) were carefully layered in an ultracentrifuge tube before OMV preparation was added on top. Ultracentrifugation was applied at approximately $246,000 \times g$ for $6 \mathrm{~h}$, and then, 1-ml aliquots were collected from top to bottom and were transferred into separate tubes. Each 1-ml sample was diluted with water to a final volume of $12 \mathrm{ml}$ and was then spun down again at approximately $170,000 \times g$ for $2 \mathrm{~h}$. The final pellet was resuspended with $0.5 \mathrm{ml}$ of water. To estimate OMV concentration, we used the Bradford assay (Pierce) to measure total protein content in OMV preparations. OMV concentrations used in subsequent assays refer to this protein-based value (Manning and Kuehn 2011).

\section{SDS-PAGE and Western blot analysis.}

OMV samples prepared as described above $(20 \mu \mathrm{l})$ were separated on either $12 \%$ or 4 to $12 \%$ SDS-PAGE gels (Bio-Rad) and were then stained with Coomassie blue stain to visualize total protein. For Western blot analysis, SDS-PAGE gels were blotted onto polyvinylidene diflouride membranes. We used the PXO_03968 protein (formerly Ax21) as a marker protein for the OMV fraction and detection was carried out using an anti-Ax21 antibody, as described previously (Bahar et al. 2014). In brief, the Ax21 antibody and a secondary antirabbit immunoglobulin $\mathrm{G}$ antibody coupled to horseradish peroxidase were used at dilutions of 1:3,000 and 1:5,000, respectively, in combination with chemilumenesence substrates (Pierce ECL Western Blotting Substrate) to detect proteins by exposure to X-ray films.

\section{TEM analysis.}

OMV samples were negatively stained using $4 \%$ uranyl acetate on $\mathrm{Cu}-400 \mathrm{FC}$ grids. Specimens were analyzed using a Philips CM120 Biotwin Lens (F.E.I. Company) and Gatan MegaScan, model 794/20, digital camera (2K X 2K) (Gatan BioScan, model 792).

\section{ROS burst assays.}

Twelve leaf discs ( $4 \mathrm{~mm}$ in diameter) per treatment of three 4- to 5-week-old plants were sampled using a cork borer and were incubated overnight in a 96-well plate containing sterile water. The following day, the water was replaced with a solution of luminol, $17 \mathrm{mg} / \mathrm{ml}$ (wt/vol) (Sigma), and horseradish peroxidase (Sigma), $10 \mathrm{mg} / \mathrm{ml}$, containing $30 \mu \mathrm{g}$ of $X$. campestris pv. campestris OMVs per milliliter or $100 \mathrm{nM}$ elf18. Luminescence was captured using a Berthold microplate reader (Berthold Technologies).

Defense-gene induction assays with Arabidopsis seedlings.

Arabidopsis seedlings were grown as described above. At $24 \mathrm{~h}$ before OMV or peptide challenge, the MS medium was removed and $250 \mu \mathrm{l}$ of water was added to each well. Seedlings were then incubated overnight at room temperature. The next morning, $20 \mu \mathrm{l}$ (at the indicated concentration) of OMVs, control peptide (flg22 or elf 18 at final concentration of $100 \mathrm{~nm}$ ), or water was added to each well. Unless stated otherwise, seedlings were treated with $X$. campestris pv. campestris-purified OMVs and were incubated for $6 \mathrm{~h}$. Following incubation, seedlings were pulled out, were blotted dry on a clean absorbent paper, and were snap-frozen in liquid nitrogen for further RNA extraction, cDNA synthesis, and defense-gene expression analysis. In all experiments, at least three wells representing three biological replicates consisting of a total of six seedlings were used for each treatment. In some experiments, OMVs were boiled for $10 \mathrm{~min}$ or proteinase K-treated at $37^{\circ} \mathrm{C}$ for $60 \mathrm{~min}$. To remove the broken peptides from OMV digest, vesicles were washed three times with $5 \mathrm{ml}$ of water and three rounds of centrifugation $(150,000 \times g$, $60 \mathrm{~min}$ ). As controls, we used the supernatant of the final wash and an OMV sample that was not treated with proteinase $\mathrm{K}$ but underwent the exact same centrifugation and washing steps as the treated sample.

\section{RNA extraction, qRT-PCR, and statistical analysis.}

Total RNA was isolated from Arabidopsis seedlings, using the TRIzol reagent (Invitrogen), following the manufacturer's instructions. RNA was treated with DNase I (Ambion) to remove possible genomic DNA traces and was then used for first-strand cDNA synthesis, using the Invitrogen reverse transcription kit (Invitrogen) or the TIANScript RT kit (Tiangen). qRT-PCR was performed using a Bio-Rad CFX96 real-time system coupled to a C1000 thermal cycler (Bio-Rad) or with a 7500 Fast real-time PCR system (Applied Biosystems). For qRT-PCR reactions, the Bio-Rad SsoFast EvaGreen supermix (Bio-Rad) or the Fast SYBR Green master mix (Applied Biosystems) were used. For quantitative defense-gene activation, we used two marker genes, FRK1 and At5g57220, and ubiquitin as a reference gene, as described previously (Schwessinger et al. 2011). qRT-PCR was performed using the following primer sets: qFRK1_F and R (5'-ATCTTCGCTTGGAGCTTCTC-3' and 5'-TGCAGCGCAAG GACTAGAG), qAt5g57220_F and R (5'-AATGGAGAGAGC AACACAATG- $3^{\prime}$ and 5'-ATACTGAGCATGAGCCCTTTG-3') and qUBQ10_F and R (5'-AGATCCAGGACAAGGAGGTATTC$3^{\prime}$ and $5^{\prime}$-CGCAGGACCAAGTGAAGAGTAG-3'). Two technical replicates were performed for each biological replicate. The score of each biological replicate is the average of the two technical replicates and the average of each treatment was calculated from the three biological replicates. Statistical analysis was performed with the JMP software (SAS Institute Inc.), using the appropriate statistical test indicated.

\section{Plant cell cultures and alkalinization response.}

Cell cultures of Arabidopsis WT (from accession Ler-0) and the efr bakl double mutant (Col-0 background) were maintained and used for experiments four to eight days after subculture, as described before (Felix et al. 1999). To measure the alkalinization response, 1-ml aliquots of the cell suspensions were placed in open $20-\mathrm{ml}$ vials on a rotary shaker at 120 cycles per minute. Using small combined glass electrodes, the extracellular $\mathrm{pH}$ was either recorded continuously with a pen recorder or measured after $30 \mathrm{~min}$ of treatment, as indicated. 


\section{ACKNOWLEDGMENTS}

The authors thank G. Coaker for valuable comments during the preparation of this manuscript and for supplying mutant lines efr-1, fls 2 , and efr fls2, A. Gust for supplying mutant lines lym1-1 and lym3-1, C. Zipfel for supplying mutant line bak1-5, and Y. Zhang for supplying mutant line sobir1-12. We also thank $\mathrm{Y}$, Nguyen for technical assistance and $\mathrm{J}$. Heazlewood for critical review of the manuscript. The work of O. Bahar was supported by postdoctoral award number FI-433-2010 from BARD, the United States-Israel Binational Agricultural Research and Development Fund. The work of B. Schwessinger was supported by a Human Frontier Science Program long-term postdoctoral fellowship (LT000674/2012) and a Discovery Early Career Award (DE150101897) from the Australian Research Council. The work at PCR lab was supported by a National Institutes of Health grant GM 59962. Work at the O. Bahar lab was supported by the German-Israeli Foundation for Scientific Research and Development (GIF), grant number I-2392-203.13/2015. Contribution number 558/16 from the Agricultural Research Organization, Volcani Center, Bet Dagan, Israel.

\section{LITERATURE CITED}

Aslam, S. N., Newman, M. A., Erbs, G., Morrissey, K. L., Chinchilla, D., Boller, T., Jensen, T. T., De Castro, C., Ierano, T., Molinaro, A., Jackson, R. W., Knight, M. R., and Cooper, R. M. 2008. Bacterial polysaccharides suppress induced innate immunity by calcium chelation. Curr. Biol. 18: 1078-1083.

Bahar, O., and Burdman, S. 2010. Bacterial fruit blotch: A threat to the cucurbit industry. Isr. J. Plant Sci. 58:19-31.

Bahar, O., Goffer, T., and Burdman, S. 2009. Type IV pili are required for virulence, twitching motility, and biofilm formation of acidovorax avenae subsp. citrulli. Mol. Plant-Microbe Interact 22:909-920.

Bahar, O., Pruitt, R., Luu, D. D., Schwessinger, B., Daudi, A., Liu, F., Ruan, R., Fontaine-Bodin, L., Koebnik, R., and Ronald, P. 2014. The Xanthomonas Ax 21 protein is processed by the general secretory system and is secreted in association with outer membrane vesicles. PeerJ 2:e242.

Bomberger, J. M., MacEachran, D. P., Coutermarsh, B. A., Ye, S., O’Toole, G. A., and Stanton, B. A. 2009. Long-distance delivery of bacterial virulence factors by Pseudomonas aeruginosa outer membrane vesicles. PLoS Pathog. 5:e1000382.

Bonnington, K. E., and Kuehn, M. J. 2014. Protein selection and export via outer membrane vesicles. Biochim. Biophys. Acta - Mol. Cell Res. 1843: $1612-1619$

Cao, Y., Liang, Y., Tanaka, K., Nguyen, C. T., Jedrzejczak, R. P., Joachimiak, A., and Stacey, G. 2014. The kinase LYK5 is a major chitin receptor in Arabidopsis and forms a chitin-induced complex with related kinase CERK1. eLife 3:1-19.

Chowdhury, C., and Jagannadham, M. V. 2013. Virulence factors are released in association with outer membrane vesicles of Pseudomonas syringae pv. tomato T1 during normal growth. Biochim. Biophys. Acta. Proteins Proteomics 1834:231-239.

Chutkan, H., Macdonald, I., Manning, A., and Kuehn, M. J. 2013. Quantitative and qualitative preparations of bacterial outer membrane vesicles. Methods Mol. Biol. 966:259-272.

Dodds, P. N., and Rathjen, J. P. 2010. Plant immunity: Towards an integrated view of plant-pathogen interactions. Nat. Rev. Genet. 11:539-548.

Ellis, T. N., and Kuehn, M. J. 2010. Virulence and immunomodulatory roles of bacterial outer membrane vesicles. Microbiol. Mol. Biol. Rev. 74:8194.

Ellis, T. N., Leiman, S. A., and Kuehn, M. J. 2010. Naturally produced outer membrane vesicles from Pseudomonas aeruginosa elicit a potent innate immune response via combined sensing of both lipopolysaccharide and protein components. Infect. Immun. 78:3822-3831.

Felix, G., Duran, J. D., Volko, S., and Boller, T. 1999. Plants have a sensitive perception system for the most conserved domain of bacterial flagellin. Plant J. 18:265-276.

Gao, M., Wang, X., Wang, D., Xu, F., Ding, X., Zhang, Z., Bi, D., Cheng, Y. T., Chen, S., Li, X., and Zhang, Y. 2009. Regulation of cell death and innate immunity by two receptor-like kinases in Arabidopsis. Cell Host Microbe 6:34-44.

Gómez-Gómez, L., and Boller, T. 2000. FLS2: An LRR receptor-like kinase involved in the perception of the bacterial elicitor flagellin in Arabidopsis. Mol. Cell 5:1003-1011.

Ionescu, M., Zaini, P. A., Baccari, C., Tran, S., da Silva, A. M., and Lindow, S. E. 2014. Xylella fastidiosa outer membrane vesicles modulate plant colonization by blocking attachment to surfaces. Proc. Natl. Acad. Sci. U.S.A. 111:E3910-E3918.

Jäger, J., Keese, S., Roessle, M., Steinert, M., and Schromm, A. B. 2014. Fusion of Legionella pneumophila outer membrane vesicles with eukaryotic membrane systems is a mechanism to deliver pathogen factors to host cell membranes. Cell. Microbiol. 17:1-29.

Jehle, A. K., Furst, U., Lipschis, M., Albert, M., and Felix, G. 2013a. Perception of the novel MAMP eMax from different Xanthomonas species requires the Arabidopsis receptor-like protein ReMAX and the receptor kinase SOBIR. Plant Signal. Behav. 8:11-13.

Jehle, A. K., Lipschis, M., Albert, M., Fallahzadeh-Mamaghani, V., Fürst, U., Mueller, K., and Felix, G. 2013b. The receptor-like protein ReMAX of Arabidopsis detects the microbe-associated molecular pattern eMax from Xanthomonas. Plant Cell 25:2330-40.

Kadurugamuwa, J. L., and Beveridge, T. J. 1996. Bacteriolytic effect of membrane vesicles from Pseudomonas aeruginosa on other bacteria including pathogens: Conceptually new antibiotics. J. Bacteriol. 178: 2767-2774.

Kadurugamuwa, J. L., and Beveridge, T. J. 1998. Delivery of the nonmembrane-permeative antibiotic gentamicin into mammalian cells by using Shigella flexneri membrane vesicles. Antimicrob. Agents Chemother. 42:1476-1483

Kaparakis, M., Turnbull, L., Carneiro, L., Firth, S., Coleman, H. A., Parkington, H. C., Le Bourhis, L., Karrar, A., Viala, J., Mak, J., Hutton, M. L., Davies, J. K., Crack, P. J., Hertzog, P. J., Philpott, D. J., Girardin, S. E., Whitchurch, C. B., and Ferrero, R. L. 2010. Bacterial membrane vesicles deliver peptidoglycan to NOD1 in epithelial cells. Cell. Microbiol. 12:372-385.

Kaparakis-Liaskos, M., and Ferrero, R. L. 2015. Immune modulation by bacterial outer membrane vesicles. Nat. Rev. Immunol. 15:375-387.

Kesty, N. C., Mason, K. M., Reedy, M., Miller, S. E., and Kuehn, M. J. 2004. Enterotoxigenic Escherichia coli vesicles target toxin delivery into mammalian cells. EMBO J. 23:4538-4549.

Kuehn, M. J., and Kesty, N. C. 2005. Bacterial outer membrane vesicles and the host-pathogen interaction. Genes Dev. 19:2645-2655.

Kulp, A., and Kuehn, M. J. 2010. Biological functions and biogenesis of secreted bacterial outer membrane vesicles. Annu. Rev. Microbiol. 64: 163-184.

Kunze, G., Zipfel, C., Robatzek, S., Niehaus, K., Boller, T., and Felix, G. 2004. The $\mathrm{N}$ terminus of bacterial elongation factor $\mathrm{Tu}$ elicits innate immunity in Arabidopsis plants. Plant Cell 16:3496-3507.

Liebrand, T. W. H., van den Berg, G. C. M., Zhang, Z., Smit, P., Cordewener, J. H. G., America, A. H. P., America, A. H. P., Sklenar, J., Jones, A. M. E., Tameling, W. I. L., Robatzek, S., Thomma, B. P. H. J., and Joosten, M. H. A. J. 2013. Receptor-like kinase SOBIR1/EVR interacts with receptor-like proteins in plant immunity against fungal infection. Proc. Natl. Acad. Sci. U.S.A. 110:10010-5.

Liebrand, T. W. H., van den Burg, H. A., and Joosten, M. H. A J. 2014. Two for all: Receptor-associated kinases SOBIR1 and BAK1. Trends Plant Sci. 19:123-132.

MacDonald, I. A., and Kuehn, M. J. 2012. Offense and defense: Microbial membrane vesicles play both ways. Res. Microbiol. 163:607-618.

MacDonald, I. A., and Kuehn, M. J. 2013. Stress-induced outer membrane vesicle production by Pseudomonas aeruginosa. J. Bacteriol. 195:29712981.

Manning, A. J., and Kuehn, M. J. 2011. Contribution of bacterial outer membrane vesicles to innate bacterial defense. BMC Microbiol. 11:258

Mashburn, L. M., and Whiteley, M. 2005. Membrane vesicles traffic signals and facilitate group activities in a prokaryote. Nature 437:422-425.

McBroom, A. J., Johnson, A. P., Vemulapalli, S., and Kuehn, M. J. 2006 Outer membrane vesicle production by Escherichia coli is independent of membrane instability. J. Bacteriol. 188:5385-5392.

Miya, A., Albert, P., Shinya, T., Desaki, Y., Ichimura, K., Shirasu, K., Narusaka, Y., Kawakami, N., Kaku, H., and Shibuya, N. 2007. CERK1, a LysM receptor kinase, is essential for chitin elicitor signaling in Arabidopsis. Proc. Natl. Acad. Sci. U.S.A. 104:19613-19618.

Nekrasov, V., Li, J., Batoux, M., Roux, M., Chu, Z. H., Lacombe, S., Rougon, A., Bittel, P., Kiss-Papp, M., Chinchilla, D., van Esse, H. P., Jorda, L., Schwessinger, B., Nicaise, V., Thomma, B. P., Molina, A., Jones, J. D., and Zipfel, C. 2009. Control of the pattern-recognition receptor EFR by an ER protein complex in plant immunity. EMBO J. 28:3428-3438.

Newman, M. A., Dow, J. M., Molinaro, A., and Parrilli, M. 2007. Priming, induction and modulation of plant defence responses by bacterial lipopolysaccharides. J. Endotoxin Res. 13:69-84.

Park, K. S., Lee, J., Jang, S. C., Kim, S. R., Jang, M. H., Lötvall, J., Kim, Y. K., and Gho, Y. S. 2013. Pulmonary inflammation induced by bacteria-free outer membrane vesicles from Pseudomonas aeruginosa. Am. J. Respir. Cell Mol. Biol. 49:637-45.

Pérez-Cruz, C., Carrión, O., Delgado, L., Martinez, G., López-Iglesias, C., and Mercade, E. 2013. New type of outer membrane vesicle produced by the gram-negative bacterium Shewanella vesiculosa M7T: Implications for DNA content. Appl. Environ. Microbiol. 79:1874-1881. 
Ranf, S., Gisch, N., Schäffer, M., Illig, T., Westphal, L., Knirel, Y. A, Sánchez-Carballo, P. M., Zähringer, U., Hückelhoven, R., Lee, J., and Scheel, D. 2015. A lectin S-domain receptor kinase mediates lipopolysaccharide sensing in Arabidopsis thaliana. Nat. Immunol. 16:426-433.

Renelli, M., Matias, V., Lo, R. Y., and Beveridge, T. J. 2004. DNAcontaining membrane vesicles of Pseudomonas aeruginosa PAO1 and their genetic transformation potential. Microbiology 150:2161-2169.

Ronald, P. C., and Beutler, B. 2010. Plant and animal sensors of conserved microbial signatures. Science 330:1061-1064.

Sambrook, J., Fritsch, E. F., and Maniatis, T. J. 1989. Molecular Cloning: A Laboratory Manual. Cold Spring Harbor Laboratory Press, New York.

Schooling, S. R., and Beveridge, T. J. 2006. Membrane vesicles: An overlooked component of the matrices of biofilms. J. Bacteriol. 188: 5945-5957.

Schwessinger, B., and Rathjen, J. P. 2015. Changing SERKs and priorities during plant life. Trends Plant Sci. 20:531-533.

Schwessinger, B., Roux, M., Kadota, Y., Ntoukakis, V., Sklenar, J., Jones, A., and Zipfel, C. 2011. Phosphorylation-dependent differential regulation of plant growth, cell death, and innate immunity by the regulatory receptor-like kinase BAK1. PLoS Genet. 7:e1002046.

Sharpe, S. W., Kuehn, M. J., and Mason, K. M. 2011. Elicitation of epithelial cell-derived immune effectors by outer membrane vesicles of nontypeable Haemophilus influenzae. Infect. Immun. 79:4361-4369.

Sidhu, V. K., Vorhölter, F.-J., Niehaus, K., and Watt, S. A. 2008. Analysis of outer membrane vesicle associated proteins isolated from the plant pathogenic bacterium Xanthomonas campestris pv. campestris. BMC Microbiol. 8:87.

Silipo, A., Molinaro, A., Sturiale, L., Dow, J. M., Erbs, G., Lanzetta, R., Newman, M. A., and Parrilli, M. 2005. The elicitation of plant innate immunity by lipooligosaccharide of Xanthomonas campestris. J. Biol. Chem. 280:33660-33668.

Smith, J. M., and Heese, A. 2014. Rapid bioassay to measure early reactive oxygen species production in Arabidopsis leave tissue in response to living Pseudomonas syringae. Plant Methods 10:6.

Solé, M., Scheibner, F., Hoffmeister, A.-K., Hartmann, N., Hause, G., Rother, A., Jordan, M., Lautier, M., Arlat, M., and Büttner, D. 2015. Xanthomonas campestris pv. vesicatoria secretes proteases and xylanases via the Xps-type II secretion system and outer membrane vesicles. J. Bacteriol. 197:2879-2893.
Sun, Y., Li, L., Macho, A. P., Han, Z., Hu, Z., Zipfel, C., Zhou, J.-M., and Chai, J. 2013. Structural basis for flg22-induced activation of the Arabidopsis FLS2-BAK1 immune complex. Science 342:624-628.

Tans-Kersten, J., Huang, H., and Allen, C. 2001. Ralstonia solanacearum needs motility for invasive virulence on tomato. J. Bacteriol. 183:3597-3605.

Tellström, V., Usadel, B., Thimm, O., Stitt, M., Küster, H., and Niehaus, K. 2007. The lipopolysaccharide of Sinorhizobium meliloti suppresses defense-associated gene expression in cell cultures of the host plant Medicago truncatula. Plant Physiol. 143:825-37.

Wengelnik, K., Marie, C., Russel, M., and Bonas, U. 1996. Expression and localization of HrpA1, a protein of Xanthomonas campestris pv. vesicatoria essential for pathogenicity and induction ofthe hypersensitive reaction. J. Bacteriol. 178:1061-1069.

Willmann, R., Lajunen, H. M., Erbs, G., Newman, M. A., Kolb, D., Tsuda K., Katagiri, F., Fliegmann, J., Bono, J. J., Cullimore, J. V., Jehle, A. K., Gotz, F., Kulik, A., Molinaro, A., Lipka, V., Gust, A. A., and Nurnberger, T. 2011. Arabidopsis lysin-motif proteins LYM1 LYM3 CERK1 mediate bacterial peptidoglycan sensing and immunity to bacterial infection. Proc. Natl. Acad. Sci. U.S.A. 108:19824-19829.

Zhang, W., Fraiture, M., Kolb, D., Löffelhardt, B., Desaki, Y., Freddy, F. G. Tör, M., Zipfel, C., Gust, A. A., andBrunner, F. 2013. Arabidopsis receptor-like protein30 and receptor-like kinase supressor of BIR1-1 / EVERSHED mediate innate immunity to necrotrophic fungi. Plant Cell 25:4227-4241.

Zhang, L., Kars, I., Essenstam, B., Liebrand, T. W. H., Wagemakers, L., Elberse, J., Tagkalaki, P., Tjoitang, D., van den Ackerveken, G., and van Kan, J. A. L. 2014. Fungal endopolygalacturonases are recognized as microbe-associated molecular patterns by the arabidopsis receptor-like protein RESPONSIVENESS TO BOTRYTIS POLYGALACTURONASES1. Plant Physiol. 164:352-64.

Zipfel, C. 2014. Plant pattern-recognition receptors. Trends Immunol. 35: 345-351.

Zipfel, C., and Felix, G. 2005. Plants and animals: A different taste for microbes? Curr. Opin. Plant Biol. 8:353-360.

Zipfel, C., Kunze, G., Chinchilla, D., Caniard, A., Jones, J. D., Boller, T., and Felix, G. 2006. Perception of the bacterial PAMP EF-Tu by the receptor EFR restricts Agrobacterium-mediated transformation. Cell $125: 749-760$ 